\title{
Perceptions of Virtual Team Communication Effectiveness: The Role of Team Member Identity Motives and Media Characteristics
}

\author{
Christina Hymer \\ University of South Carolina \\ Christina.Hymer@grad.moore.sc.edu
}

\author{
Susan Brown \\ University of Arizona \\ suebrown@arizona.edu
}

\author{
Sherry Thatcher \\ University of South Carolina \\ Sherry.Thatcher@moore.sc.edu
}

\begin{abstract}
Although much research has examined how individuals convey their identities to others at work and outcomes related to identity communication, we know little about outcomes associated with identity communication in virtual settings. In this study, we examine the relationship between professionals' motives for communicating their identities to others and their perceptions of virtual team communication effectiveness. In doing so, we consider the moderating role of features of the communication media (information control, reach, reprocessability) on these relationships. We find that three motives (self-protection, self-creation, and self-enhancement) relate to team members' perceptions of communication effectiveness. We also find evidence for the influence of communication media features on several of these relationships. We provide an overview of our data collection methodology and results, concluding with theoretical and practical implications.
\end{abstract}

\section{Introduction}

While employers have increasingly turned to virtual teams over the past decade [1], the Covid-19 pandemic has further forced many employers to reevaluate their talent management strategies and adopt the usage of virtual teams [2]. As a number of scholars have noted, the virtual context shifts how team members coordinate and conduct work compared to traditional face-to-face teams [1]. Interpersonal issues (e.g., distrust, injustice perceptions) and team member differences (e.g., family responsibilities) become salient within virtual teams and may break down team communication processes [3-5].

Managers of face-to-face teams can help combat these issues by fostering a sense of connectedness among team members [6]. Employees' efforts to convey their identities to each other builds interpersonal relationships and shapes other important organizational outcomes, including job satisfaction, organizational citizenship, and positive social relationships at work [7-10]. However, a reliance on computer-mediated technology challenges identity communication processes and requires a novel way of thinking about identity communication within virtual teams [11-13]. We cannot assume that identity communication operates in the same manner in virtual contexts as it does in face-to-face contexts because the technology may complicate how people communicate their identities. Given the importance of identity communication in fostering organizational outcomes, it is critical that scholars gain a solid understanding of this phenomenon within virtual teams. We highlight team member identity motives and features of the communication media to provide a novel perspective on communication effectiveness within virtual teams.

Overall, we suggest that team members who seek to communicate their identities to others will also report higher levels of communication effectiveness within their virtual teams, with this relationship influenced by features of the team's communication media. We test this assertion using a multi-source sample of individuals within virtual project teams. Our study contributes to research on identity motives and virtual team outcomes, specifically team communication effectiveness. Practically, our findings imply that managers ought to foster a safe communication climate for virtual team members and carefully consider communication media offered to employees.

The goal of this paper is to develop a new theory on virtual identity communication and its relationship with perceived team communication effectiveness. We provide a description of extant relevant literature, followed by our hypotheses. We then discuss our data collection methodology and the results of our analysis. We conclude by providing theoretical and practical implications of our study. Our findings underscore the importance of considering team member and communication media attributes when examining virtual team communication.

\section{Background}


Identity provides the answer to "Who am I?" [14]. In general, people have an underlying need to communicate their identities and have them verified by others [15], as this communication facilitates a sense of continuity, coherence, and a feeling of being understood [16]. Identity communication, when communicated and received by a sender, predicts many individual and group outcomes like individual satisfaction and group creativity, as well as the overall success of a team [9, 17]. In face-to-face settings, employees communicate identities in a variety of ways, such as physical displays of identityrelated objects (e.g., family pictures, professional awards, hobby-related paraphernalia, sports-team merchandise), dress, and conscious decisions about behavior or communication style $[18,19]$.

Prior work in face-to-face group settings finds that effective identity communication produces individual and group benefits. For example, identity communication fosters social resources for individuals and facilitates their career development and growth [8]. Effective identity communication can also increase individuals' capacity to deal with challenges at work [20], predict judgments [21], improve creativity [22, 23], and promote social integration [9]. Effective identity communication has been linked to individual satisfaction, meaning, and self-worth at work [10, 24], which makes workers more motivated to act in the interest of their teams [9] and organizations [7]. Effective identity communication has also been shown to lead to more information sharing and trust [7, 25]. Research suggests that team members who understand each others' identities perform at higher levels [9, 16, 17], cooperate [26], feel connected [19], behave authentically, and direct effort towards achieving group outcomes [9]. In fact, effective identity communication has been suggested as one of the key mechanisms determining whether diversity helps or hinders a group [9]. In short, identity communication relates to a plethora of positive group outcomes, many of which rely upon clear communication channels within teams. For these reasons, we anticipate that virtual team members who are motivated to convey their identities to others are more likely to report communication effectiveness within their teams.

We find that despite the rise of virtual teams, most research on identity communication focuses on those working within face-to-face teams. One exception is Thatcher and colleagues' [27] recent work where they introduced the concept of virtual identity communication. While their study highlights the role of identity motives in predicting virtual identity communication and identity relevance, our study builds off of their findings to examine the role of individuals' identity motives and a team's media characteristics in predicting perceived virtual team communication effectiveness. In line with their work and following Vignoles and colleagues' [28, p. 320] definition of identity communication (i.e., "the extent to which individuals strive to communicate each of their identity elements to others in everyday life"), we define virtual identity communication as the process of conveying one's identity to other team members within a virtual environment. We define team communication effectiveness as the extent that team members are able to openly communicate and understand each other when coordinating on tasks $[29,30]$.

\section{Hypotheses Development}

In this section, we provide a theory of identity communication in virtual teams. We now consider team members' motives for communicating their identities to others and media characteristics that are important for examining virtual team communication effectiveness. Figure 1 provides an overview of our model.

\subsection{Identity Motives}

Identity motives refer to "pressures toward certain identity states and away from others, which guide the processes of identity construction" [28, p. 309). The extent and content of workers' identity communications are determined by their identity motives [31]. While there is a dizzying list of identity motives [32], we focus on a central identity motive self-enhancement - and two identity motives that are relevant within the virtual context: self-protection and self-creation [27]. To that end, these identity motives are necessary to account for unique features of virtual contexts. In contrast to face-to-face contexts, the virtual context opens up avenues to construct additional selves, regardless of accuracy, but presents greater risk and privacy concerns about communicated identity information. We focus on the relationship between identity motives and perceived team communication effectiveness, as communicating one's identity means that one is establishing communication lines that facilitate team communication effectiveness. We now provide a brief overview of these three motives.

Self-protection represents the need for safety of one's communicated identity [27]. Individuals in face-to-face contexts are aware of who receives their identity information, as their identity 
communications are restricted to those within their immediate vicinity. However, virtual identity communications may be more dispersed than face-toface communications and consequently more prone to risk and privacy concerns [33]. As a result, individuals in virtual contexts who are high in selfprotection may be motivated to protect communications pertaining to their virtual identity from unintended recipients and from possible distortion. Because workers motivated by the selfprotection identity motive are less likely to communicate identity information online, such individuals are also less likely to form virtual relationships with other team members resulting in fewer team communication channels and less effective virtual team communication. Thus, we anticipate a negative relationship between the selfprotection identity motive and a team member's perception of virtual team communication as effective.

Self-creation, on the other hand, is likely to foster perceptions of effective virtual team communication. Individuals motivated by self-creation are driven to generate and share a new version of the "self" to others $[27,34,35]$. We suggest that the self-creation motive will manifest in virtual organizational contexts more prominently than in face-to-face contexts. This is supported by previous research that has highlighted channels within the virtual organizational context, like personal home pages [36, 37] and virtual avatars (e.g., [38]), that allow team members to construct identities for themselves. Because such representations may not align with one's actual self [39], the virtual organizational context allows individuals to project alternate versions of the self. The self-creation motive indicates a willingness to communicate one's identities and form interpersonal relationships with team members. Interpersonal relationships among team members are especially important when coordinating and collaborating on tasks, ultimately impacting perceptions of team communication effectiveness [40]. We argue that because identity communication fosters the formation of interpersonal relationships among team members, those who seek to communicate identity information are more likely to also perceive effective team communication. Thus, we anticipate a positive relationship between the selfcreation identity motive and perceived virtual team communication effectiveness.

Self-enhancement refers to the desire to view oneself positively relative to others [41-43]. Selfenhancement manifests in many ways, including strategic self-presentation or impression management [44], biased self-evaluations (sometimes called the "above-average effect") [43], selective memory focused on one's positive traits or experiences [45], and the self-serving bias, in which positive outcomes are attributed to one's own traits or actions while negative outcomes are blamed on others or circumstances [46]. With self-enhancement behaviors so commonplace in organizations, some scholars suggest that self-enhancement is the primary motive guiding identification [43]. Individuals driven by the self-enhancement motive are motivated to communicate their identities to others within virtual contexts, as identity communication provides a means of conveying and cementing one's position relative to others. Because identity communication also fosters the development of interpersonal relationships within teams, we anticipate that those motivated by the self-enhancement identity motive are likely to consequently perceive virtual team communication as effective.

In summary, we propose three relevant identity motives as predictors of perceived virtual team communication effectiveness. We anticipate the following:

H1: Individuals motivated by the (a) self-creation and self-enhancement motives will perceive virtual team communication as more effective, while those motivated by the (b) self-protection motive will perceive virtual team communication as less effective.

\subsection{Media Characteristics}

We draw from prior work on communication media to identify characteristics that will affect the virtual team communication process. Several theories related to media characteristics can be found in the literature, including media richness theory, media synchronicity theory [47, 48], and the impression management model of communication channels [49]. We do not explicitly incorporate these prior media theories in our model, but instead consider the media characteristics they develop in order to describe communication media in a manner that aligns with previous work. We argue that these media characteristics moderate the relationship between team members' identity motives and their perceptions regarding the effectiveness of team communication.

We hypothesize moderating effects for the selfprotection and self-enhancement identity motives, but not for the self-creation identity motive. Because the self-creation motive involves a desire to establish and convey a new version of oneself to others, we anticipate that this motive prompts an introspective, cognitive process that is less likely to interact with communication media than motives involving 
existing identities (self-protection, selfenhancement). The self-protection and selfenhancement motives, in turn, reflect beliefs regarding existing identities and are thus more vulnerable to features of the communication media than the self-creation motive which involves a notyet-formed identity.

We focus on three relevant media characteristics: information control, reprocessability, and reach. We anticipate that each of these media characteristics shape the relationship between self-protection and perceived virtual team communication effectiveness. However, while we anticipate that the relationship between self-enhancement and perceived virtual team communication effectiveness is shaped by information control, we do not hypothesize the influence of reprocessability or reach on this relationship. Although the ability to control the positivity of one's narrative is likely important for understanding the relationship between selfenhancement and perceived virtual team communication effectiveness, reach and reprocessability refer to the dispersion and reproduction of information, which are unlikely to affect one's ability to generate a positive identity narrative.

Information control. Information control refers to the extent to which a particular medium allows individuals "to regulate or restrict the flow of social information during interactions over a medium of interpersonal communication" [50, p. 116). Information control is similar to a medium's rehearsability as defined in MST-the extent to which a sender can practice and/or modify the message before it is communicated [48] - but it is broader in scope. Specifically, in addition to the control over a message's content, tone, and appearance afforded by rehearsability, information control also refers to control regarding who will receive the message. Some technologies allow one to clearly specify and target a message for a specific individual or group (e.g., email), whereas others support less specificity (e.g., a blog post). Situations in which an individual has greater control over the recipients of a message and its interpretation are associated with increased usage and self-presentation [49-51]. Thus, information control should be highly relevant for virtual identity communication, since media affording such control will allow users to carefully construct their identity-related messages based on their understanding of who will be able to access their messages.

Furthermore, if a user desires to communicate a certain identity, it should be beneficial to be able to refine or edit the message prior to sending. Such control allows the individual to precisely present the desired identity. An example of such behavior would be the careful reading of an email prior to sending to ensure proper grammar and spelling, which could communicate personal identities related to competence, writing ability, or attention to detail [52]. Based on O'Sullivan's [49] impression management model of communication channels, information control should influence users' decisions about whether to engage in virtual identity communication. Because information control provides individuals with greater say over the content of their communications, we expect that those motivated by the self-protection motive will feel safer communicating identity information when their team communication media contains high information control. Likewise, we expect that those motivated by self-enhancement will feel that they can better control their identity narrative and present a more positive image of themselves to others when their team communication media contains high information control. Thus, we anticipate the following:

$\mathrm{H} 2$ : Individuals working in virtual teams with media containing high information control will report an a) attenuated negative relationship between self-protection and their perceptions of virtual team communication as effective and b) strengthened positive relationship between selfenhancement and their perceptions of virtual team communication as effective.

Reach. We define a technology's reach as the perception that the technology provides the opportunity to send messages to a large, rather than small, audience. This concept has surfaced in other discussions of media choice, such as when organizations choose certain media for marketing purposes that are perceived to be cost-efficient in reaching a large set of potential customers [53]. Media with high reach enables users with the opportunity to communicate information to a large target group (sending an email via a company-wide email distribution list, for example), whereas media with low reach enables communication to only a small target group (sending an instant message to a single employee). However, because those motivated by the self-protection motive are likely to feel security concerns regarding communicating their identities online, a communication media's reach may amplify those concerns. For instance, a communication media's reach may enable identity information to be ultimately distributed to audiences beyond those whom a team member is familiar with. For these reasons, we hypothesize the following:

H3: Individuals working in virtual teams with media containing high reach will report a 
strengthened negative relationship between selfprotection and their perceptions of virtual team communication as effective.

Reprocessability. Reprocessability is the ability for a communicator to review prior interactions [48]. This capability improves information processing on the receiving end and should also influence users' identity communication processes. A technology that makes prior communications accessible to users would allow other team members to carefully interpret and re-examine identity-related information. Similar capabilities in online communities increase community members' perceptions of identity verification [25], and have been identified as relevant features in organizational use of social media [54]. A salient example of this type of reprocessable identity communication is a profile page (e.g., on Facebook or LinkedIn) where users can purposefully present information about themselves in the form of pictures, background information, achievements, certifications, and so on that are preserved within that media. However, a downside of reprocessability is that such retained information may be inaccurate and/or potentially damaging to one's identity. Thus, we anticipate that those motivated by self-protection will perceive more risk involved within team communications when their team's communication media contains high reprocessability. In summary, we hypothesize:

H4: Individuals working in virtual teams with media containing high reprocessability will report a strengthened negative relationship between self-protection and their perceptions of virtual team communication as effective.

\section{Methodology}

We collected data from professionals who work within project teams that utilize computer-mediated tools for communication (e.g., Skype, Slack, Zoom, e-mail). We obtained multi-source data, recruiting professionals taking part in a professional MBA program $(\mathrm{n}=55)$ and workers on Amazon Mechanical Turk ('MTurk') ( $\mathrm{n}=194)$. Given that identity motives are considered stable across time [28], the nature of our model did not require data from multiple time periods. Thus, we surveyed participants at a single time period.

We screened for participants who participate within project teams and who are currently part of at least one project team that uses computer-mediated tools for task communication. We then asked participants to describe one project team within their job that mainly uses computer-mediated tools for task participation and instructed them to answer subsequent survey questions in reference to that project team. We employed two attention checks (e.g., "Please select 'strongly agree"') and removed participants who failed at least one of those checks [55].

We adapted Vignoles and colleague's [28] measurement approach for identity motives to assess participants' needs for self-protection, self-creation, and self-enhancement. This involved asking participants to list five identities that are important to them within their team, and then several questions regarding the extent to which each of those identities fulfill their self-protection, self-creation, and selfenhancement motives (e.g., "To what extent do each of the following identities give you a sense of selfesteem within your team?"). We averaged participants' responses to these questions across each of their five identities to obtain a mean score for their self-protection, self-creation, and self-enhancement motives.

We measured media characteristics using established and newly-developed scales. We used 8 items from Feaster's [50] information control scale (e.g., "I can avoid topics that I don't want to discuss"; alpha $=.70)$. We created three items to measure reprocessability ("My team uses communication tools that allow us to reexamine the messages that are shared", "The communication tools used by my team allow me to revisit prior messages", "The communication tools used by my team provide a memory of our communication"), with a Cronbach's alpha of .80 . We created three items to measure the reach of participants' computer-mediated communication tools ("My team uses communication tools that enable messages to be sent to a large audience", "My team uses communication tools that target large groups", "My team uses communication tools that allow me to send information to many people"), with a Cronbach's alpha of .83. Finally, we adapted three items from Lowry and colleagues' [56] communication openness measure ("It is easy to communicate openly to all members of this team", "Communication in this team is very open", and "When people communicate to each other in this team, there is a great deal of understanding" and added a new item, "Time spent in team interactions is efficiently used") to measure team members' perceptions of virtual team communication effectiveness. We use a measure of communication openness, as our definition of team communication effectiveness refers to the extent that there is an open communication culture within virtual teams. As mentioned earlier, we define virtual team communication effectiveness as the extent that team members are able to openly communicate and 
understand each other when coordinating on tasks.

Cronbach's alpha was .84. We controlled for whether participants were recruited from our professional MBA student sample or MTurk ('Source').

Table 1. Regression Results: Predicting Perceived Virtual Team Communication Effectiveness

\begin{tabular}{|c|c|c|c|c|c|c|c|c|c|}
\hline \multirow[b]{3}{*}{ (Intercept) } & \multirow{3}{*}{$\begin{array}{l}\text { Coef. } \\
5.71778\end{array}$} & \multicolumn{2}{|l|}{ Model 1} & \multicolumn{3}{|c|}{ Model 2} & \multicolumn{2}{|c|}{ Model 3} & \multirow[b]{2}{*}{ Std.Error } \\
\hline & & p-value & Std.Error & Coef. & p-value & Std.Error & Coef. & p-value & \\
\hline & & $* * *$ & 0.06977 & 5.69652 & $* * *$ & 0.06878 & 5.58576 & $* * *$ & 0.07011 \\
\hline Source & -0.46778 & $* *$ & 0.14845 & -0.37152 & $*$ & 0.15264 & -0.18571 & & 0.14862 \\
\hline Self-protection & & & & -0.12311 & $*$ & 0.06039 & -0.15753 & $*$ & 0.0607 \\
\hline Self-creation & & & & 0.18063 & $* *$ & 0.06708 & 0.18589 & $* *$ & 0.06322 \\
\hline Self-enhancement & & & & 0.22844 & $*$ & 0.10273 & 0.15758 & & 0.10065 \\
\hline \multicolumn{10}{|l|}{ Information } \\
\hline control & & & & & & & 0.31566 & $* * *$ & 0.08767 \\
\hline Reach & & & & & & & 0.11296 & $*$ & 0.0502 \\
\hline Reprocessability & & & & & & & 0.10424 & & 0.06401 \\
\hline \multicolumn{10}{|l|}{ Self-protection X } \\
\hline \multicolumn{10}{|l|}{ Information } \\
\hline control & & & & & & & 0.1476 & $\dagger$ & 0.07578 \\
\hline \multicolumn{10}{|l|}{ Self-enhancement } \\
\hline \multicolumn{10}{|l|}{ X Information } \\
\hline control & & & & & & & 0.26615 & $*$ & 0.12959 \\
\hline \multicolumn{10}{|l|}{ Self-protection X } \\
\hline Reach & & & & & & & 0.10662 & $*$ & 0.05212 \\
\hline \multicolumn{10}{|l|}{ Self-protection X } \\
\hline Reprocessability & & & & & & & -0.17529 & $* *$ & 0.06167 \\
\hline
\end{tabular}

Notes. $N=249 . \dagger=\mathrm{p}<.10 ; *=p<.05 ; * *=p<.01 ; * * *=p<.001$.

\section{Analysis}

The model was analyzed using OLS regression techniques. Table 1 provides a summary of our findings.

In Hypothesis 1, we predicted that individuals motivated by the self-creation and self-enhancement motives will perceive virtual team communication as more effective whereas those motivated by the selfprotection motive will perceive virtual team communication as less effective. We find support for this hypothesis.

In Hypothesis 2, we predicted that information control weakened the negative relationship between self-protection and team members' perceptions of virtual team communication as effective and strengthened the positive relationship between selfenhancement and team members' perceptions of virtual team communication as effective. We find support for the moderating effect of information control on the relationship between self-enhancement and perceived virtual team communication effectiveness. However, our results do not attain standard levels of statistical significance for the moderating effect of information control on the relationship between self-protection and team communication effectiveness $(p=.053)$. To that end, Hypothesis 2 is partially supported. Thus, media that affords team members control over their identity narratives allows individuals to communicate more positive versions of themselves, thus enhancing the relationship between self-enhancement and one's perception of virtual team communication as effective.

In Hypothesis 3, we anticipated that the reach of a team's communication media strengthened the negative relationship between self-protection and team members' perceptions of virtual team communication as effective. Contrary to our expectations, we find that a media's reach attenuates the negative relationship between self-protection and team members' perceptions of virtual team communication as effective. One interpretation of this finding is that media with high reach provides a sense of anonymity, as the target audience may not be as well-defined as media containing a smaller reach. This expanded reach can lead to perceptions of lower social presence [57] of others in the interaction, which can ultimately lead to greater perceived safety regarding one's identity communications online. To 
that end, it is possible that media with high reach encourages identity communication, weakening the negative relationship between self-protection and team members' perceptions of virtual team communication as effective.

Finally, in Hypothesis 4, we predicted that reprocessability strengthens the negative relationship between self-protection and perceived virtual team communication effectiveness. We find support for this hypothesis. Thus, when individuals perceive that their identity information is retained and reproducible at later dates, they are less likely to report effective communication within their virtual teams.

\section{Discussion}

We argue that team members' identity motives (self-protection, self-creation, self-enhancement) relate to their perceptions of team communication as effective. We hypothesized that features of the teams' communication media (information control, reach, reprocessability) are important when examining the relationship between team members' identity motives and their perceived team communication effectiveness. We find support for a majority of our hypotheses. Our results indicate that team members driven by the self-creation and self-enhancement motives are likely to perceive virtual team communication as more effective, whereas those driven by the self-protection motive are likely to perceive team communication as less effective. We find that communication media high in information control strengthens the positive relationship between self-enhancement and team members' perceptions of team communication as effective. Contrary to our expectations, we also find that commmunication media high in reach attenuates the negative relationship between self-protection and perceived team communication effectiveness. This finding suggests that communication media with high reach promotes a sense of anonymity that buffers security concerns that those high in self-protection may feel when communicating their identities to team members. Lastly, we find that communication media high in reprocessability strengthens the negative relationship between self-protection and team members' perceptions of team communication as effective.

Overall, our study provides insight into two identity motives - self-protection and self-creation that are salient within virtual teams and are distinct from a common identity motive - self-enhancement. We argue that perceived team effectiveness is shaped by team members' identity motives, such that team members' propensity for sharing their self-definitions with others informs their perceptions of team communication effectiveness. Further, we find that features of the communication media are important within this process. We hope that our study leads to a promising program of research on identity communication within virtual teams and its relationship with perceived team communication effectiveness, as well as other important team outcomes. As the usage of virtual teams continues to rise [1], it is increasingly important to challenge the applicability of extant theories within virtual teams.

Our study make several contributions to theory. First, we examine the role of two identity motives that are important within virtual teams (selfprotection, self-creation) in understanding perceived virtual team communication effectiveness. Both motives reflect a desire to control one's identity narrative online. We find that the self-protection, self-creation, and self-enhancement motives uniquely predict team members' perceptions of team communication as effective, indicating that the selfprotection and self-creation motives are theoretically distinct from an established and central identity motive, self-enhancement. Second, we provide a fresh perspective for understanding virtual team outcomes. We theorize on the relationship between team members' propensity to communicate their identities and the content of those identity communications with their perceptions of team communication effectiveness. Because identity communication promotes a more mutual understanding of who team members are, our study highlights the important, yet understudied role of team members' identity motives when examining virtual team outcomes. Lastly, our findings imply that team members who feel comfortable conveying their identities to others also perceive higher levels of team communication effectiveness. In teams with many members motivated by the self-protection motive, it is possible that communication pathways break down, ultimately impacting other team outcomes like group performance.

Our findings also make several contributions to practice. Given that organizations are increasingly turning to virtual teams, particularly in light of the Covid-19 pandemic, it is especially important for managers to understand how team members' motives for communicating their identities relate to team outcomes. Our findings suggest that managers ought to foster a safe climate for team members to communicate their identities. Further, managers should consider the communication media that they offer to employees and norms around those media. Overall, our results indicate that managers ought to consider both the identity motives of their team 
members and features of the team's communication media when forming and managing virtual teams.

\section{Conclusion}

We have built on prior identity communication literature to present a novel perspective on the role of identity communication within virtual teams. Using multi-source data, we examine the role of team member identity motives and features of team communication media in predicting team members' perceptions of team communication effectiveness. Our findings support distinction among the selfcreation, self-protection, and self-enhancement identity motives, as well as their relationships with perceived team communication effectiveness. Our findings also highlight the value of identity communication among virtual team members in fostering perceptions of team communication effectiveness.

Despite the contributions of our study, there are several limitations which are important to discuss. First, our data contains single-source data. While identity motives are considered stable across time [28], future research may consider replicating our study using time-lagged data. Second, our data relies upon individuals' perceptions of virtual team communication effectiveness. Future research could look at objective outcomes, such as performance, or aggregate team members' perceptions of communication effectiveness to provide further tests of our model. We also encourage future research to consider how IT identity and IT culture shape virtual identity communication. IT identity, which describes the extent that one views IT usage as central to their sense of self [58], and IT culture, which reflects the IT-related behaviors, values, and assumptions shared by a group [59-61], may determine how team members' virtually communicate their identities and their willingness to do so. We look forward to future research within this exciting domain and hope that our study provides insight into how researchers and practitioners alike can better understand the determinants of successful virtual teams.

\section{References}

[1] Gilson, L. L., Maynard, M. T., Young, N. C. J., Vartiainen, M., and Hakonen, M. "Virtual teams research: 10 years, 10 themes, and 10 opportunities", Journal of Management, 41(5), 2015, pp. 1313-1337.

[2] Gardner, H. K. and Matviak, I. "Coronavirus could force teams to work remotely", https://hbr.org/2020/03/coronaviruscould-force-teams-to-workremotely, accessed July 5, 2020.

[3] Jarvenpaa, S. L., and Leidner, D. E., "Communication and trust in global virtual teams", Organization Science, 10(6), 1999, pp. 791-815.

[4] Perry, S. J., Lorinkova, N. M., Hunter, E. M., Hubbard, A., and McMahon, J. T., "When does virtuality really "work"? examining the role of work-family and virtuality in social loafing”, Journal of Management, 42(2), 2016, pp. 449-479.

[5] Thatcher, S. M. B., and Bagger, J., "Working in pajamas: Telecommuting, unfairness sources, and unfairness perceptions", Negotiation and Conflict Management Research, 4(3), 2011, pp. 248-276.

[6] Brewer, M. B., and Gardner, W., "Who is this "we"? Levels of collective identity and self representations", Journal of Personality and Social Psychology, 71(1), 1996, pp. 83-93.

[7] Dutton, J.E., Roberts, L.M., and Bednar, J., "Pathways for positive identity construction at work: Four types of positive identity and the building of social resources", Academy of Management Review, 35(2), 2010, pp. 265-293.

[8] Ibarra, H., Kilduff, M., and Tsai, W., "Zooming in and out: Connecting individuals and collectivities at the frontiers of organizational network research", Organization Science, 16(4), 2005, pp. 359-371.

[9] Polzer, J.T., Milton, L.P., and Swann, W.B., "Capitalizing on diversity: Interpersonal congruence in small work groups", Administrative Science Quarterly, 47(2), 2002, pp. 296-324.

[10] Thatcher, S.M.B., and Greer, L.L., "Does it really matter if you understand me? The implications of identity comprehension for individuals in organizations", Journal of Management, 34(1), 2008, pp. 5-24.

[11] Nelson, A.J., and Irwin, J., "Defining What We Do-All Over Again": Occupational Identity, Technological Change, and the Librarian/Internet-Search Relationship", Academy of Management Journal, 57(3), 2014, pp. 892-928.

[12] Ramarajan, L., "Past, Present and Future Research on Multiple Identities: Toward an Intrapersonal Network Approach", The Academy of Management Annals, 8(1), 2014, pp. 589-659.

[13] Thatcher, S.M., and Zhu, X., "Changing identities in a changing workplace: Identification, identity enactment, selfverification, and telecommuting", Academy of Management Review, 31(4), 2006, pp. 1076-1088.

[14] Ashforth, B.E., Harrison, S.H., and Corley, K.G., "Identification in organizations: An examination of four fundamental questions", Journal of Management, 34(3), 2008, pp. 325-374.

[15] Swann, W.B., "Self-verification: Bringing social reality into harmony with the self", in (Suls, J., and Greenwald, A.G., eds.): Psychological Perspectives on the Self, Erlbaum, Hillsdale, NJ, 1983, pp. 33-66. 
[16] Swann, W.B., Milton, L.P., and Polzer, J.T., "Should we create a niche or fall in line? Identity negotiation and small group effectiveness", Journal of personality and social psychology, 79(2), 2000, pp. 238-250.

[17] Swann, W.B., Kwan, V.S.Y., Polzer, J.T., and Milton, L.P., "Capturing the elusive "value in diversity" effect: Individuation, self-verification and performance in small groups", Personality and Social Psychology Bulletin, 29(1), 2003, pp. 1396-1406.

[18] Pratt, M. G., and Rafaeli, A. "Organizational dress as a symbol of multilayered social identities", Academy of Management Journal, 40(4), 1997, pp. 862-898.

[19] Thatcher, S.M.B., Doucet, L., and Tuncel, E., "Subjective identity and identity communication processes in information technology teams", in (Neale, M.A., E.A., M., and Polzer, J.T., eds.): Research on Managing Groups and Teams, Elsevier Science, Ltd., London, UK, 2003, pp. 53-90.

[20] Hobfoll, S. E. "Conservation of resources: A new attempt at conceptualizing stress", American Psychologist, 44(3), 1989, pp. 513-524.

[21] Reed, A., and Aquino, K., "The self-importance of moral identity", Journal of Personality and Social Psychology, 83(6), 2002, pp. 1423-1440.

[22] Beyer, J. M., and Hannah, D. R., "Building on the past: Enacting established personal identities in a new work setting", Organization Science, 13(6), 2002, pp. 636-652.

[23] Cheng, C. Y., Sanchez-Burks, J., and Lee, F. "Connecting the dots within: Creative performance and identity integration", Psychological Science, 19(11), 2008, 1178-1184.

[24] Wrzesniewski, A.C., Dutton, J.E., and Debebe, G., "Interpersonal sensemaking and the meaning of work", Research in Organizational Behavior, 25(1), 2003, pp. 93-135.

[25] Ma, M., and Agarwal, R., "Through a glass darkly: Information technology design, identity verification, and knowledge contribution in online communities", Information systems research, 18(1), 2007, pp. 42-67.

[26] Milton, L.P., and Westphal, J.D., "Identity confirmation networks and cooperation in work groups", Academy of Management Journal, 48(2), 2005, pp. 191-212.

[27] Thatcher, S., Wilson, D., and Brown, S. 2017. "(Virtual) identity communication: Motivations and contextual factors," HICSS-50, Hilton Waikoloa Village, Hawaii.

[28] Vignoles, V.L., Regalia, C., Manzi, C., Golledge, J., and Scabini, E., "Beyond self-esteem: influence of multiple motives on identity construction", Journal of Personality and Social Psychology, 90(2), 2006, pp. 308-333.

[29] Ayoko, O. B., "Communication openness, conflict events and reactions to conflict in culturally diverse workgroups", Cross Cultural Management: An International Journal, 14 (2), 2007, pp. 105-124.
[30] Lowry, P. B., Roberts, T. L., Romano, N. C., Jr., Cheney, P. D., and Hightower, R. T., "The impact of group size and social presence on small-group communication", Small Group Research, 37 (6), 2006, pp. 631-661.

[31] Ryan, R.M., and Deci, E.L., "Self-determination theory and the facilitation of intrinsic motivation, social development, and well-being", American Psychologist, 55(1), 2000, pp. 6878 .

[32] Ashforth, B. E., and Schinoff, B. S., "Identity under construction: How individuals come to define themselves in organizations", Annual Review of Organizational Psychology and Organizational Behavior, 3, 2016, pp. 111-137.

[33] Smith, H.J., Dinev, T., and Xu, H., "Information privacy research: an interdisciplinary review", MIS Quarterly, 35(4), 2011, pp. 989-1016.

[34] Zhang, P., "Motivational Affordances: Reasons for ICT Design and Use", Communications of the ACM, 51(11), 2008, pp. 145-147.

[35] Zhang, P., "Toward a positive design theory: Principles for designing motivating information and communication technologies", in (Avital, M., Boland, R.J., and Cooperrider, D.L., eds.): Designing Information and Organizations with a Positive Lens, JAI Press, Amsterdan, 2008

[36] Döring, N., "Personal home pages on the Web: A review of research", Journal of Computer-Mediated Communication, $7(3), 2002$

[37] Schau, H.J., and Gilly, M.C., "We are what we post? Self-presentation in personal web space", Journal of consumer research, 30(3), 2003, pp. 385-404.

[38] Nowak, K.L., and Rauh, C., "The influence of the avatar on online perceptions of anthropomorphism, androgyny, credibility, homophily, and attraction", Journal of ComputerMediated Communication, 11(1), 2005, pp. Article 8.

[39] Jin, S.-a.A., "The virtual malleable self and the virtual identity discrepancy model: Investigative frameworks for virtual possible selves and others in avatar-based identity construction and social interaction", Computers in Human Behavior, 28(6), 2012, pp. 2160-2168.

[40] Mathieu, J., Maynard, T. M., Rapp, T., and Gilson, L., "Team effectiveness 1997-2007: A review of recent advancements and a glimpse into the future", Journal of Management, 34(3), 2008, pp. 410-476.

[41] Hogg, M.A., Terry, D.J., and White, K.M., "A tale of two theories: A critical comparison of identity theory with social identity theory", Social Psychology Quarterly, 58(4), 1995, pp. 255-269.

[42] Sedikides, C., and Strube, M.J., "The multiply motivated self", Personality and Social Psychology Bulletin, 21(12), 1995, pp. 1330-1335.

[43] Sedikides, C., and Strube, M.J., "Self-evaluation: To thine own self be good, to thine own self be sure, to thine own self be true, and to thine own self be better", Advances in Experimental Social Psychology, 29(1997, pp. 209-269. 
[44] Leary, M.R., Self-presentation: Impression management and interpersonal behavior, Brown \& Benchmark Publishers, Madison, WI, 1995.

[45] Skowronski, J. J., Betz, A. L., Thompson, C. P., and Shannon, L., "Social memory in everyday life: Recall of selfevents and other-events", Journal of Personality and Social Psychology, 60(6), 1991, pp. 831-843.

[46] Fiedler, K., Semin, G. R., and Koppetsch, C. Language use and attributional biases in close personal relationships. Personality and Social Psychology Bulletin, 17(2), 1991, pp. 147-155.

[47] Daft, R. L., and Lengel, R. H., "Organizational information requirements, media richness and structural design”, Management Science, 32(5), 1986, pp. 554-571.

[48] Dennis, A. R., Fuller, R. M., and Valacich, J. S. "Media, tasks, and communication processes: A theory of media synchronicity”, MIS Quarterly, 32(3), 2008, pp. 575-600.

[49] O'Sullivan, B., "What you don't know won't hurt me", Human Communication Research, 26(3), 2000, 403-431.

[50] Feaster, J. C., "Expanding the impression management model of communication channels: An information control scale", Journal of Computer-Mediated Communication, 16(1), 2010, pp.115-138.

[51] Bordia, P., Irmer, B. E., and Abusah, D., "Differences in sharing knowledge interpersonally and via databases: The role of evaluation apprehension and perceived benefits", European Journal of Work and Organizational Psychology, 15(3), 2006, pp. 262-280.

[52] Brown, S. A., Fuller, R., and Thatcher, S. M. B., "Impression formation and durability in mediated communication", Journal of the Association for Information Systems, 17(9), 2016, p. 614-647.

[53] Baron, R. and Sissors, J., Advertising media planning, McGraw Hill.

[54] Treem, J. W., and Leonardi, P. M."Social media use in organizations: Exploring the affordances of visibility, editability, persistence, and association", Annals of the International Communication Association, 36(1), 2013, pp. 143-189.

[55] Porter, C. O. L. H., Outlaw, R., Gale, J. P., and Cho, T. S., "The use of online panel data in management research: A review and recommendations", Journal of Management, 45(1), 2019, pp. 319-344.

[56] Lowry, P. B., Romano, N. C., Jenkins, J. L., and Guthrie, R. W., "The CMC interactivity model: How interactivity enhances communication quality and process satisfaction in lean-media groups", Journal of Management Information Systems, 26(1), 2009, pp. 155-195.

[57] Short, J., Williams, E., and Christie, B. The social psychology of telecommunications. John Wiley \& Sons, London, UK, 1976
[58] Carter, M., and Grover, V. "Me, my self, and I(T) conceptualizing information technology identity and its implications". MIS Quarterly, 39(4), (2015), pp. 931-958.

[59] Walsh, I. "Investigating the cultural dimension of ITusage: IT-acculturation, an essential construct in IS research", International Conference on Information Systems, St. Louis, MO: Association for Information Systems, 2010.

[60] Walsh, I., Kefi, H., and Baskerville, R. "Managing culture creep: Toward a strategic model of user IT culture," Journal of Strategic Information Systems, 19(4), 2010, pp. 257-280.

[61] Walsh, I. "A strategic path to study IT use through users' IT culture and IT needs: A mixed-method grounded theory", Journal of Strategic Information Systems, 23(2), 2014, pp. 146-173. 